\title{
Un intérieur orientaliste
}

Meubles et objets d'Arthur de Gobineau conservés dans les réserves de la $\mathrm{BNU}$

Jean-Pierre Rosenkranz

\section{(2) OpenEdition}

Journals

Édition électronique

URL : https://journals.openedition.org/rbnu/3513

DOI : $10.4000 /$ rbnu.3513

ISSN : 2679-6104

Éditeur

Bibliothèque nationale et universitaire de Strasbourg

\section{Édition imprimée}

Date de publication : 1 mai 2011

Pagination : 86-99

ISSN : 2109-2761

\section{Référence électronique}

Jean-Pierre Rosenkranz, "Un intérieur orientaliste », La Revue de la BNU [En ligne], 3 | 2011, mis en ligne le 01 mai 2011, consulté le 08 août 2021. URL : http://journals.openedition.org/rbnu/3513 ; DOI : https://doi.org/10.4000/rbnu.3513

\section{(9) $(0 \Theta \odot$}

La Revue de la BNU est mise à disposition selon les termes de la Licence Creative Commons Attribution - Pas d'Utilisation Commerciale - Partage dans les Mêmes Conditions 4.0 International. 


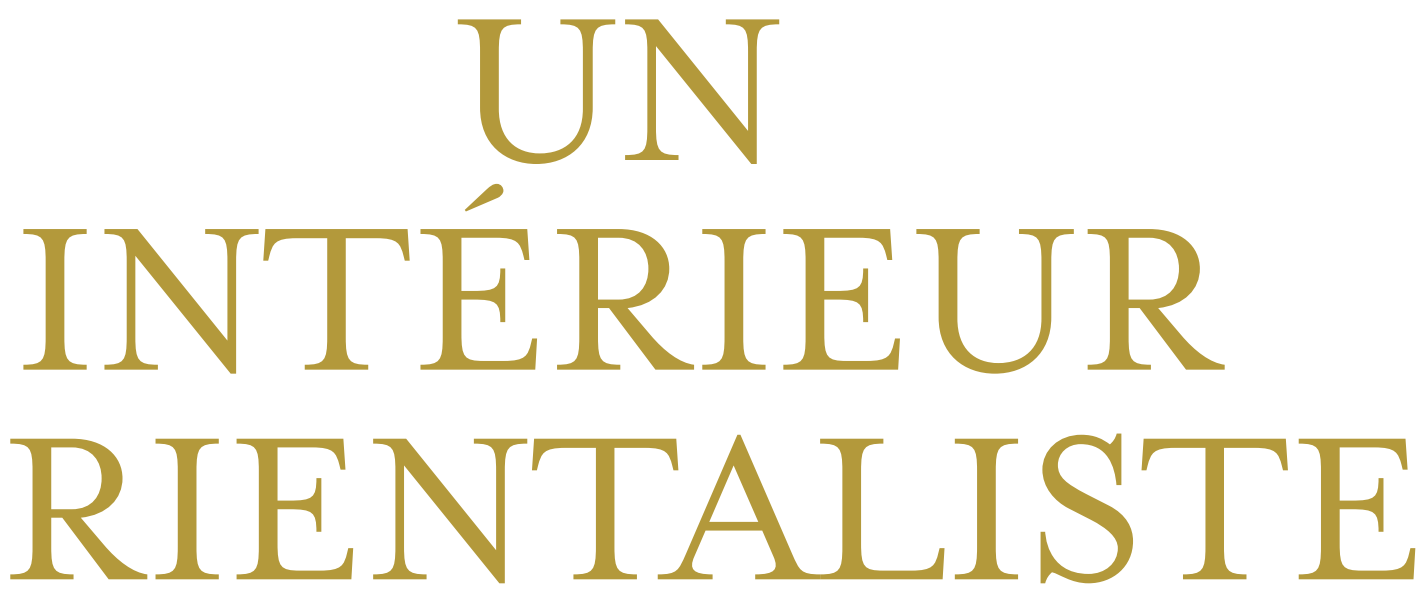

Meubles et objets d'Arthur de Gobineau conservés dans les réserves de la BNU 


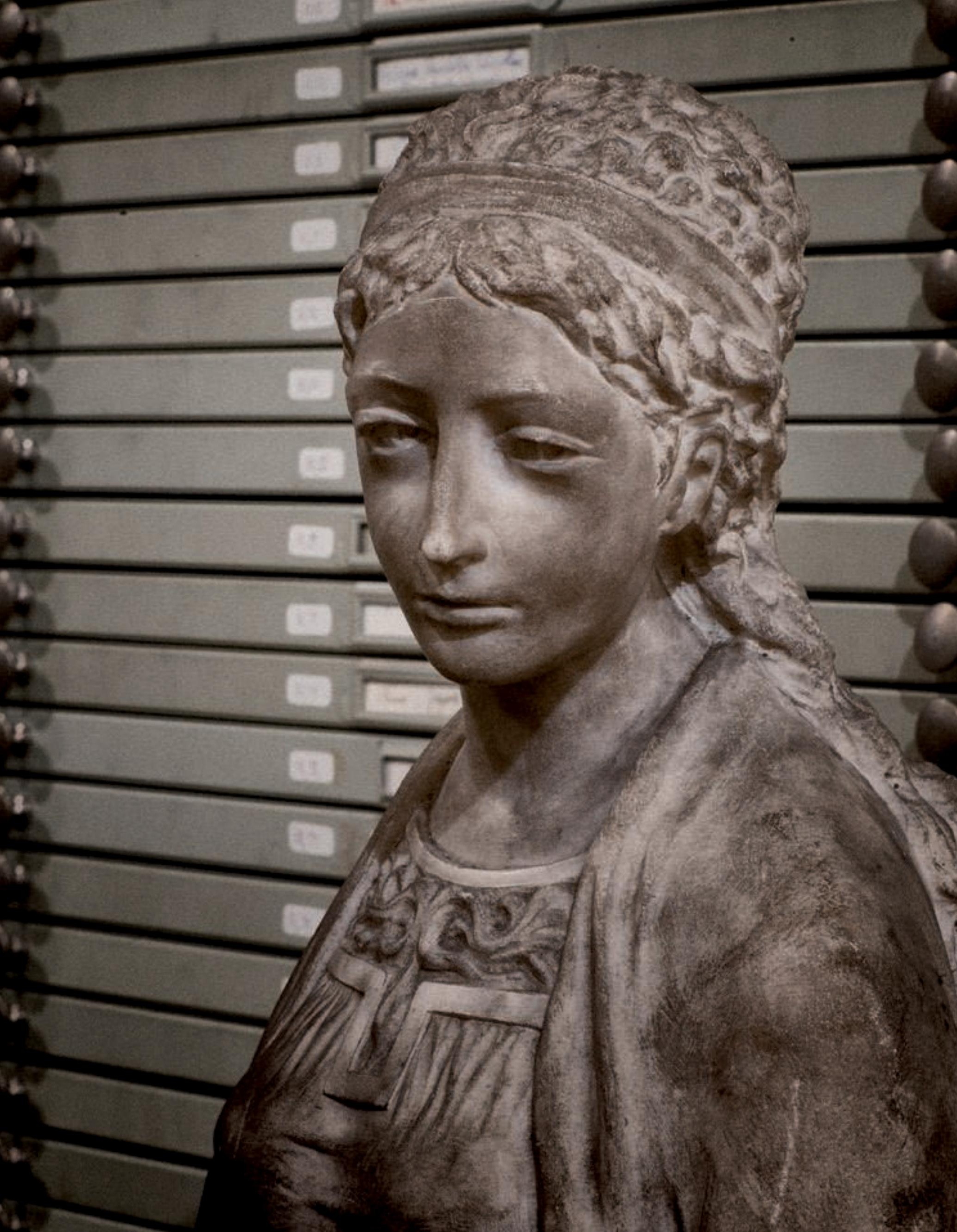




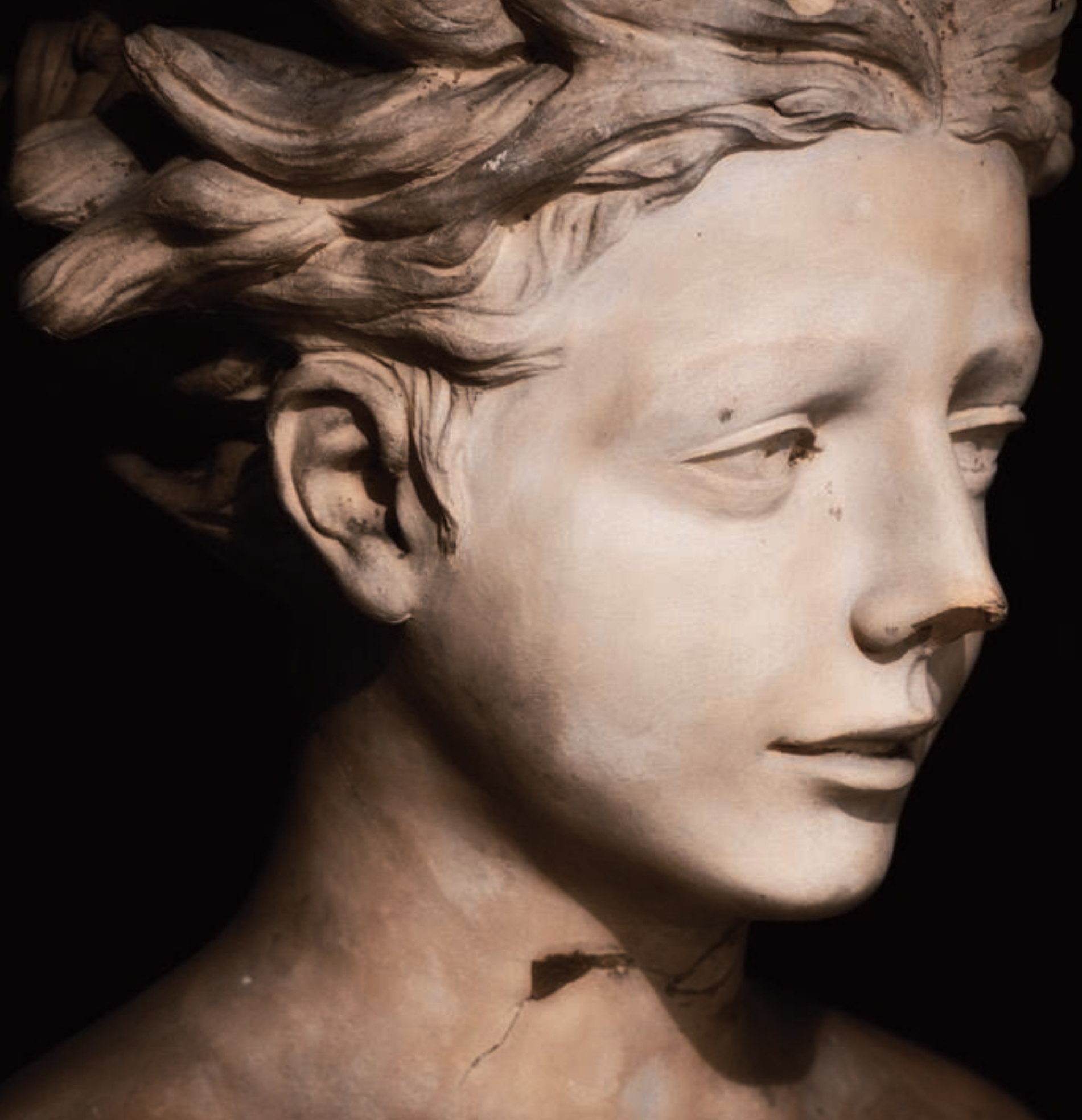




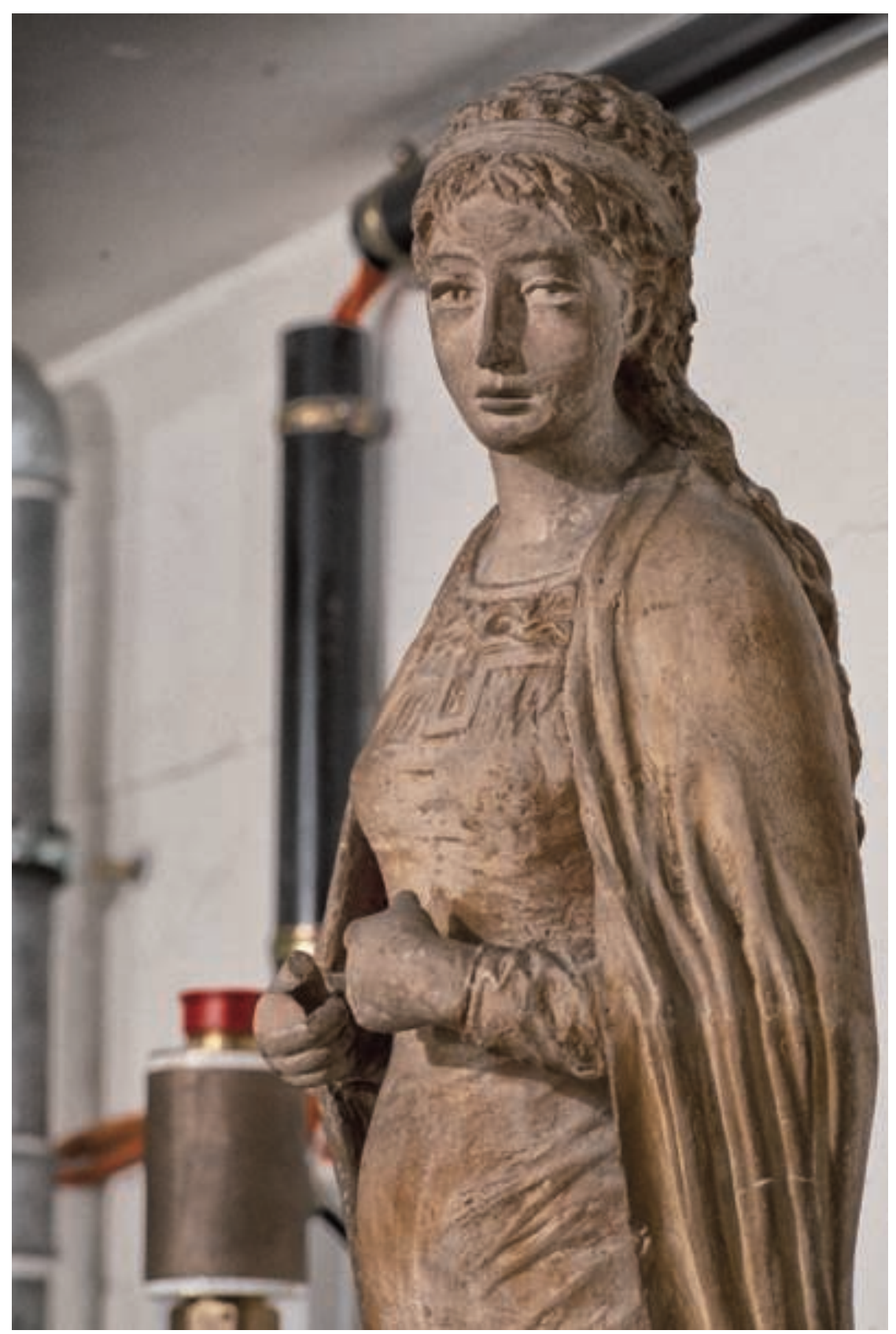

(Ci-contre) Statue en plâtre

(Ci-dessus) Statue en plâtre dans la réserve des monnaies et médailles 


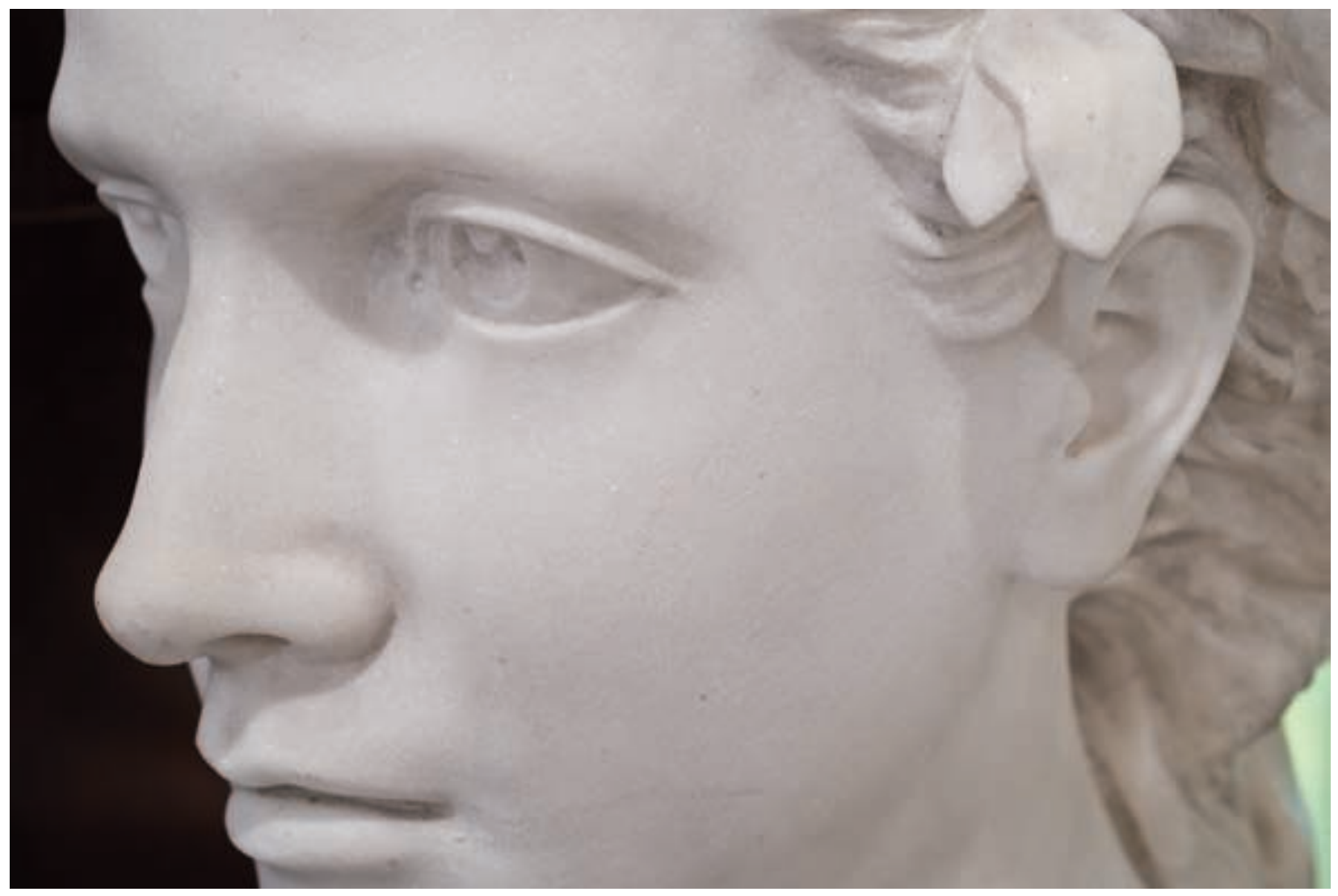

(Ci-contre) Sonata appassionata et Walkyrie vues de profil

(Ci-dessus) Détail d’une statue (marbre) 


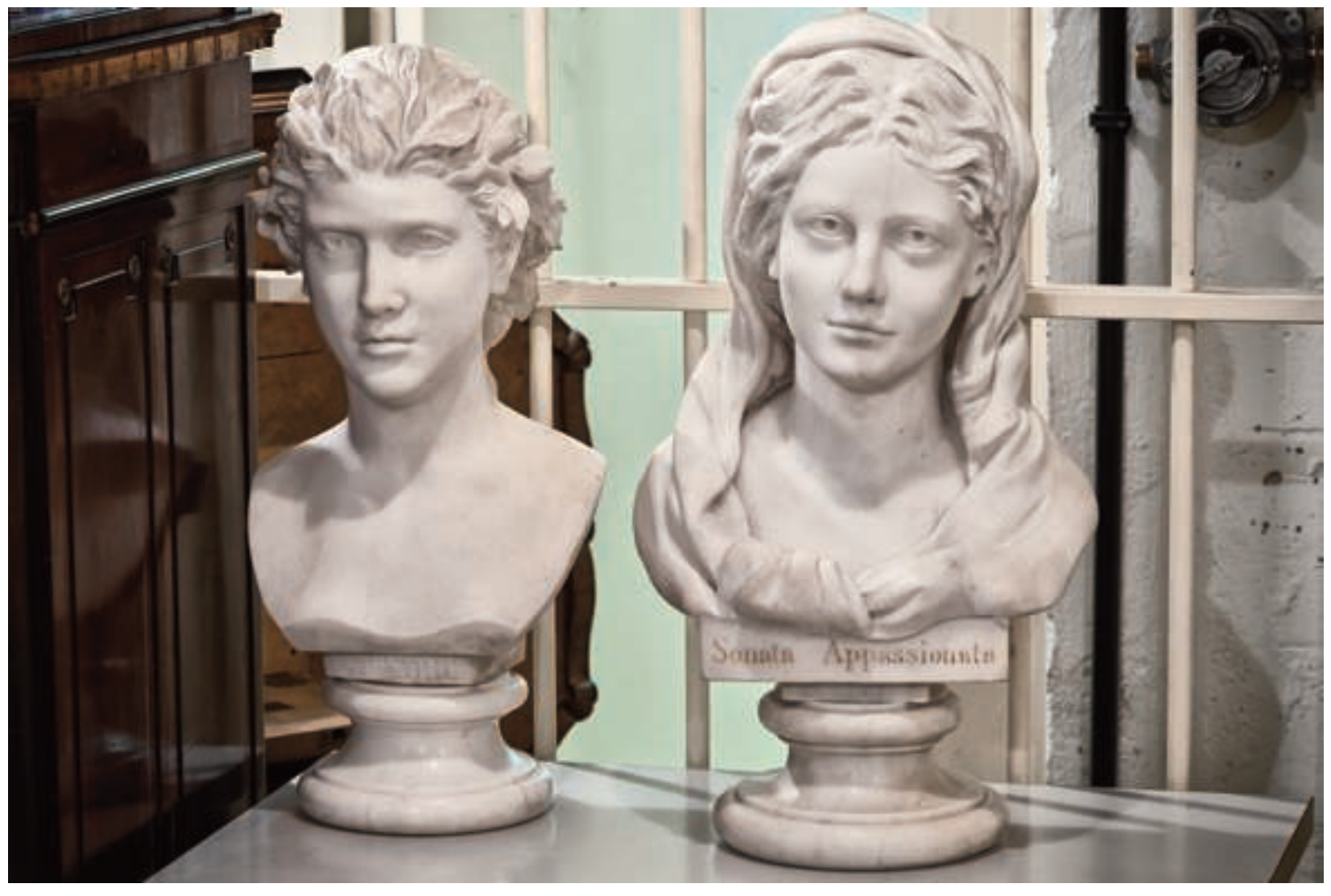




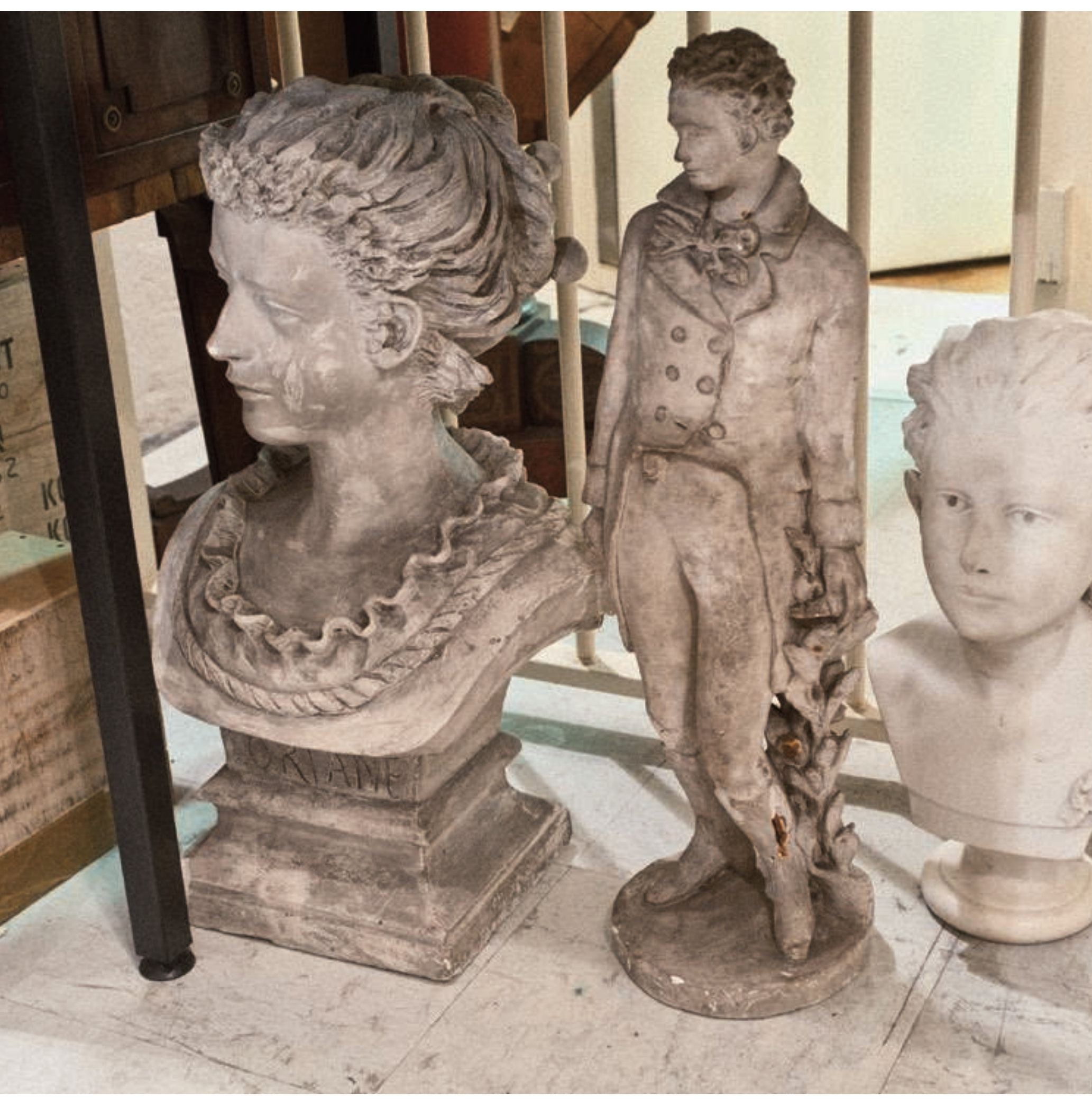




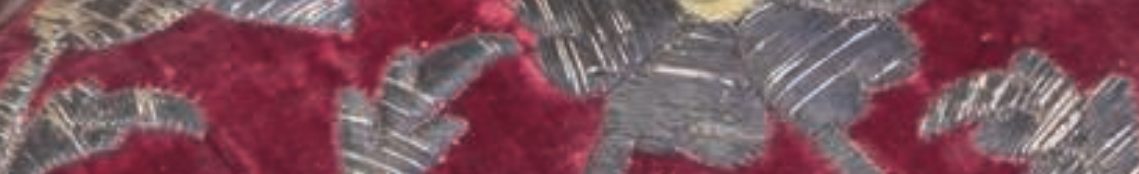

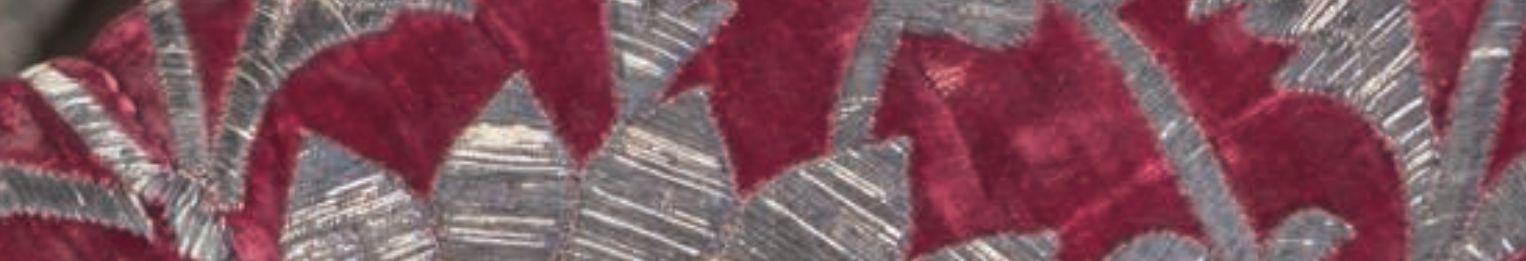

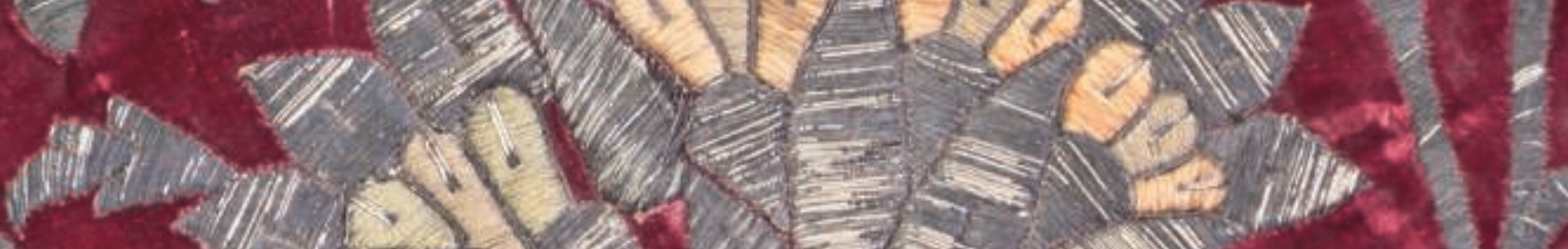

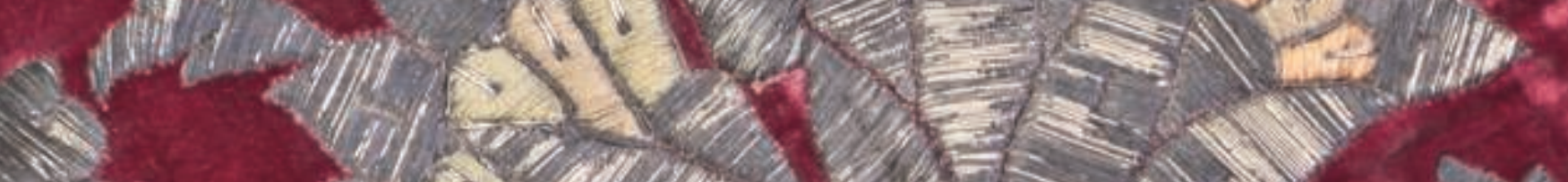

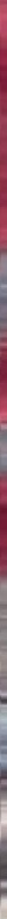

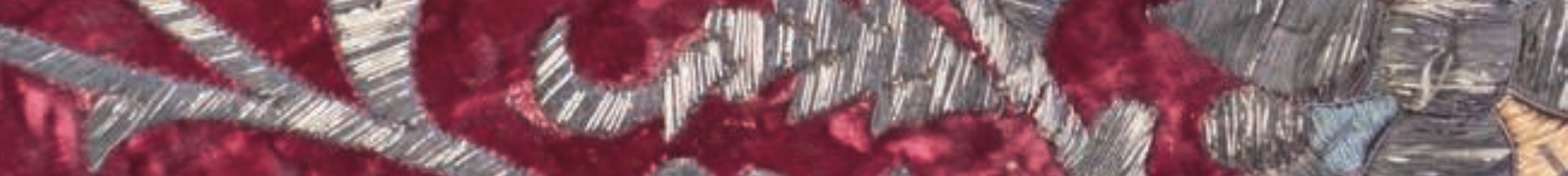

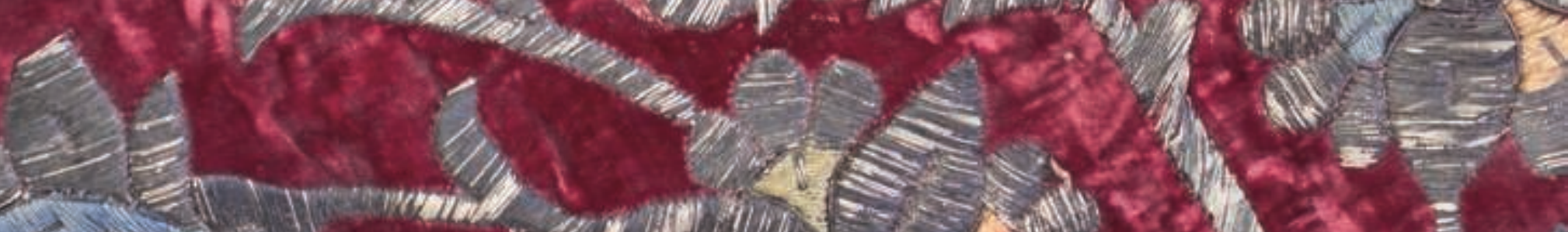

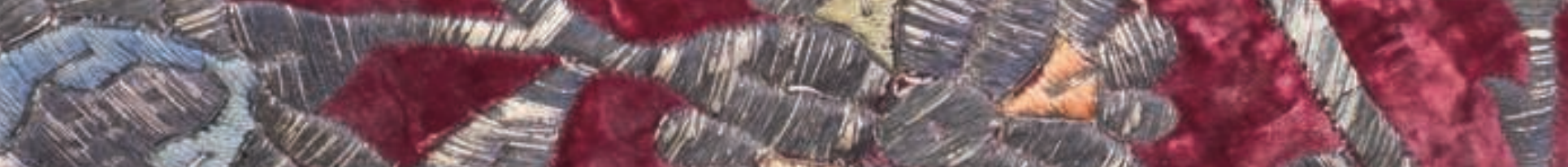

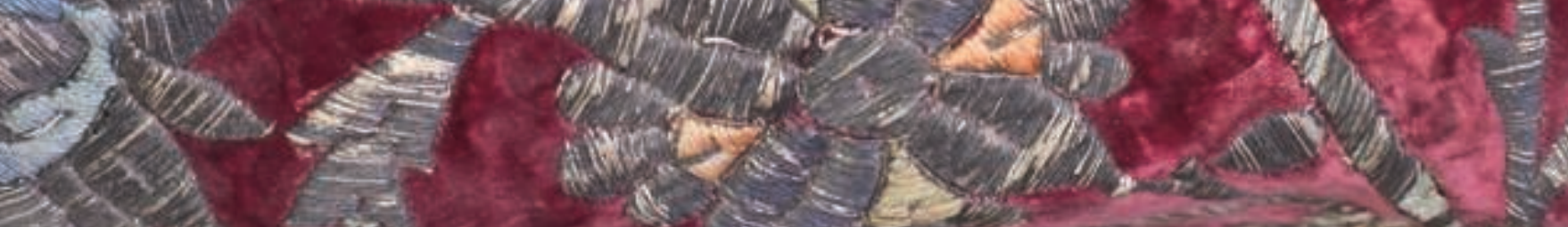




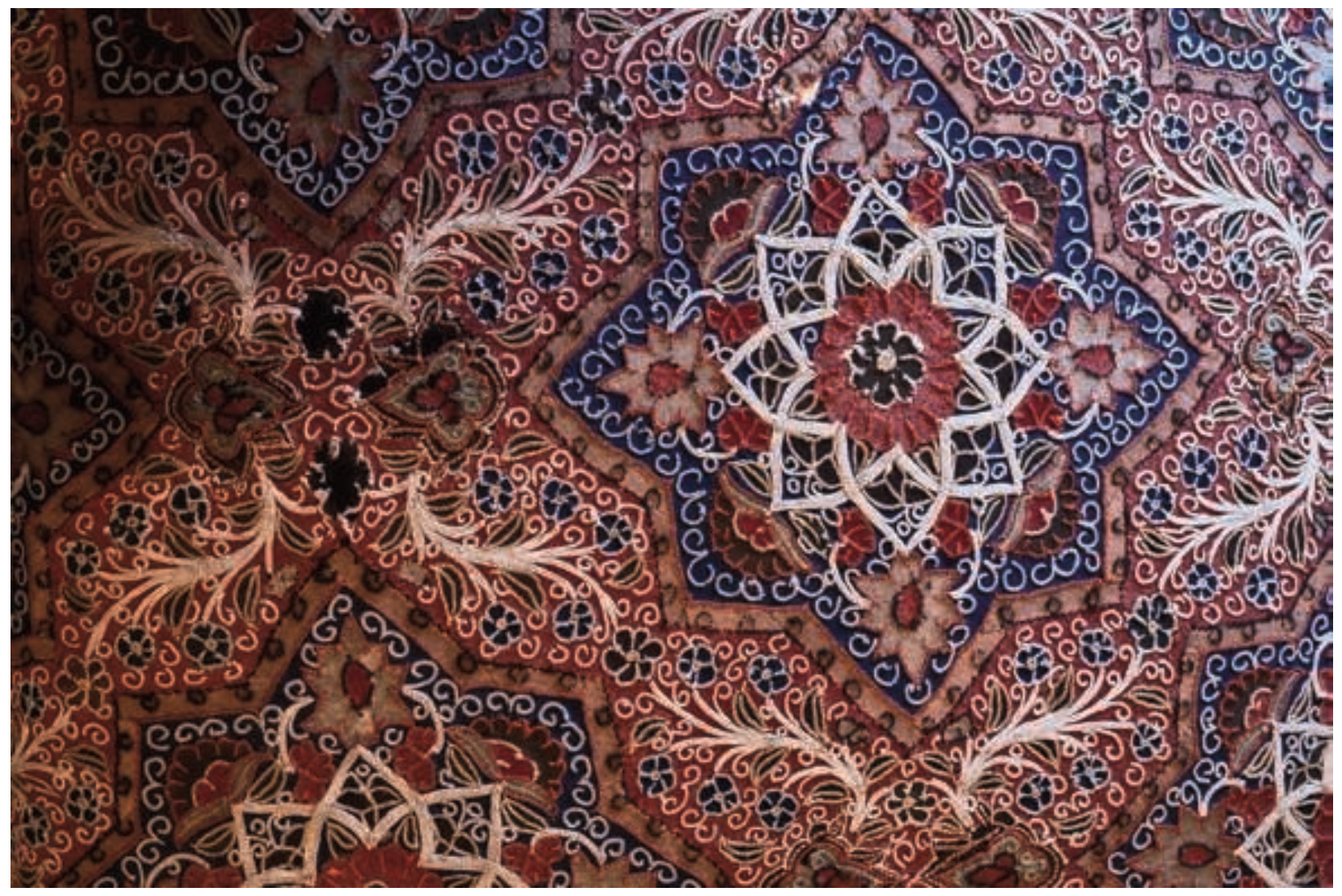

(Ci-contre) Tissu de siège (détail)

(Ci-dessus) Tapis (détail) 


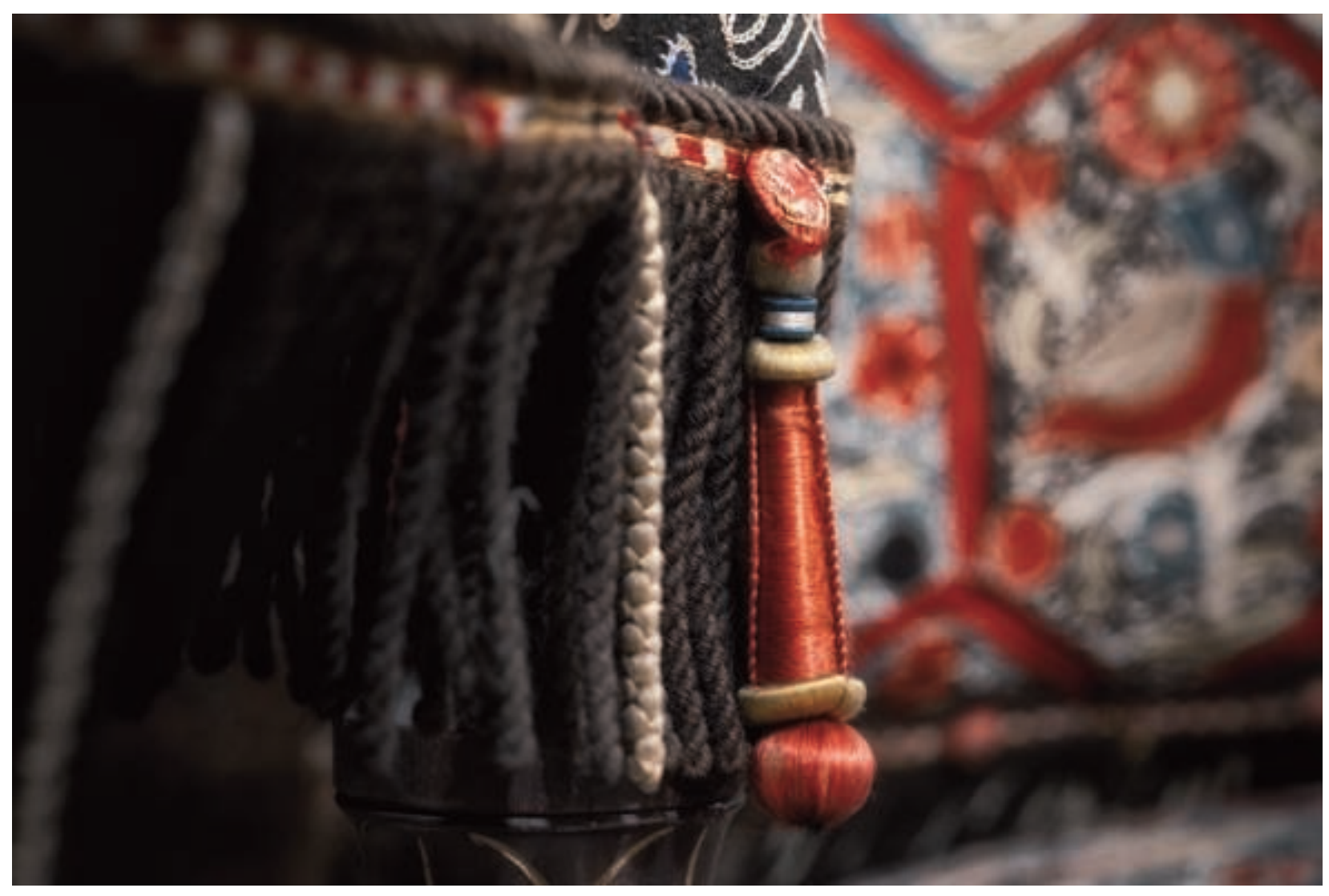

Fauteuil (détail) 


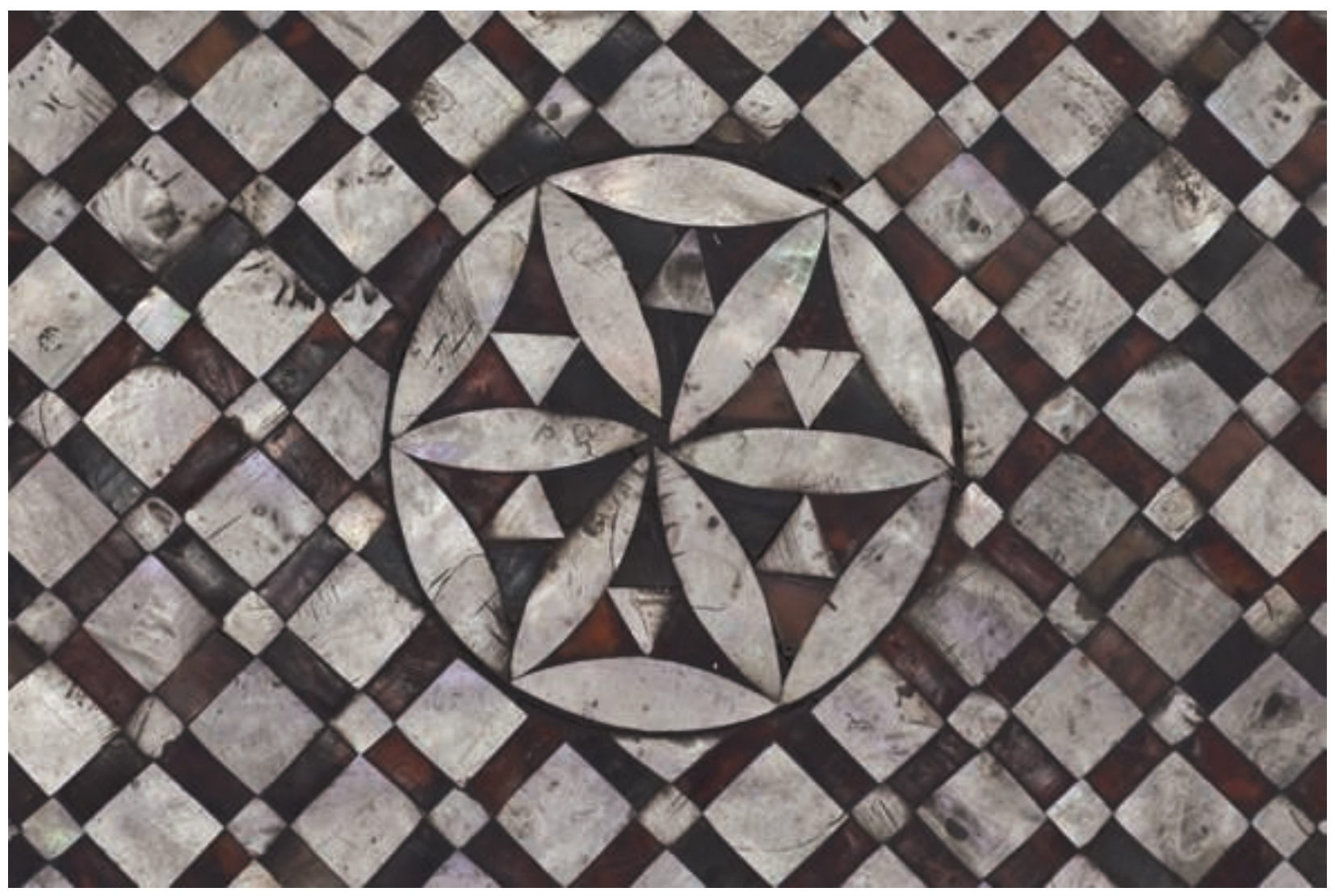

Petite table recouverte d'incrustations en nacre (détail) 


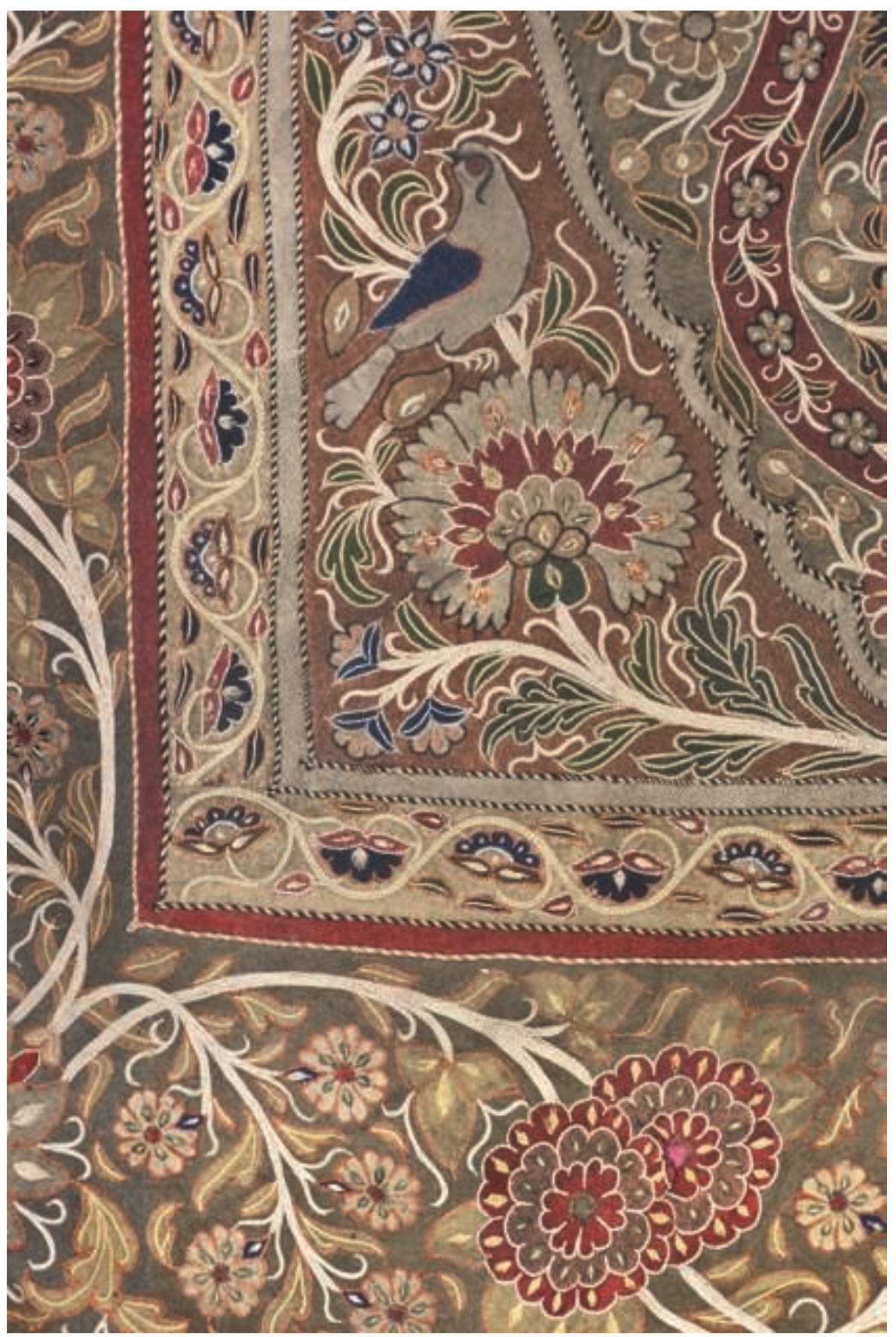


